\section{Características dos acidentes de trânsito e das vítimas atendidas em serviço pré-hospitalar em cidade do Sul do Brasil, 1997/2000}

\author{
Characteristics of traffic accidents and victims \\ treated through a pre-hospital service in a city \\ in southern Brazil, 1997/2000
}

Yara Gerber Lima Bastos 1

Selma Maffei de Andrade 1

Darli Antônio Soares 1

\footnotetext{
1 Centro de Ciências da Saúde, Universidade Estadual de Londrina, Londrina, Brasil.

Correspondência Y. G. L. Bastos Centro de Ciências da Saúde, Universidade Estadual de Londrina. Rua Alfazema 100, casa 29, Londrina, $P R$ 86061-904, Brasil. yaragerber@hotmail.com yagerber@usp.br
}

\begin{abstract}
Traffic accidents and the resulting injury and trauma constitute an important social and public health problem. The objective of this study was to analyze the characteristics of such accidents and the victims treated by the only prehospital service - the Integrated Trauma and Emergency Aid Service (SIATE) - in the city of Londrina, Paraná State, southern Brazil, from 1997 to 2000. All victims $(14,474)$ registered in the SIATE database were studied. The majority (> 70.0\%) were male and aged 10 to 39 years. Motorcyclists were the most frequent victims (> 40.0\%), and accidents occurred most frequently in December, on weekends (especially Saturdays), and at night. These results are consistent with those of other studies showing the need to implement preventive measures targeting young males, especially motorcyclists.
\end{abstract}

Traffic Accidents; Health Services; Emergency Medical Services

\section{Introdução}

O desenvolvimento industrial do século XX propiciou aumento considerável da frota de veículos automotores em circulação em todo o mundo. Especialmente após a Segunda Guerra Mundial, o carro tornou-se um objeto de consumo, e possuir um automóvel particular, um símbolo de status social, apoiado principalmente pela propaganda nas sociedades capitalistas 1,2 . Em conseqüência do aumento expressivo do número de veículos circulantes e da alta freqüência de comportamentos inadequados, aliados a uma vigilância insuficiente, os acidentes de trânsito envolvendo veículos a motor passaram a se constituir em causa importante de traumatismos na população mundial e, especialmente, na brasileira.

O trânsito, no Brasil, é considerado um dos mais perigosos do mundo, apresentando índice de um acidente para cada lote de 410 veículos em circulação, enquanto esse mesmo índice na Suécia é de um para 21.400 veículos 2 .

Londrina, Paraná, é a terceira maior cidade da Região Sul do Brasil, com uma população de cerca de 470 mil habitantes e uma taxa de urbanização de aproximadamente 97,0\% (Departamento de Informática do SUS. População residente. http://tabnet.datasus.gov.br/tabnet/tab net.htm, acessado em 15/Jan/2003). De acordo com dados do Departamento de Trânsito do Paraná (Departamento de Trânsito do Paraná. 
Listagem do número e tipo de veículos licenciados no Paraná. http://www.pr.gov.br/detran, acessado em 14/Mai/2001), a frota de veículos da cidade teve um crescimento de mais de $100,0 \%$ no período de 1986 a 2000, passando de 77.512 para 155.919 veículos. Enquanto o aumento da população de 1991 a 2000 foi de $14,5 \%$, o da frota de veículos foi de $35,2 \%$. Por essa razão, Londrina apresenta um índice de motorização bastante alto (350 veículos/mil habitantes), semelhante ao referido por Wolf 3 para os países desenvolvidos.

Esse alto índice de motorização reflete-se no perfil de morbi-mortalidade da cidade. Além de serem responsáveis por importante parcela de mortes de residentes no município, os acidentes de trânsito são também os segundos maiores responsáveis pela perda de anos potenciais de vida, sendo superados, atualmente, apenas pelos homicídios 4 .

Em termos de morbidade, embora os estudos sejam mais raros, a situação também inspira preocupação. Andrade \& Mello-Jorge 5, estudando as vítimas desses acidentes em Londrina, encontraram um coeficiente médio de incidência extremamente alto $(1.582,2$ por 100 mil habitantes).

Todos esses dados apontam os acidentes de trânsito como um problema prioritário de saúde em Londrina, pois não só constituem importante parcela das mortes prematuras, como também são responsáveis por grande parte de atendimentos de emergência em pronto-socorros e de internações hospitalares na cidade em estudo.

O Serviço Integrado de Atendimento ao Trauma e às Emergências (SIATE) foi criado em junho de 1996, por meio de uma parceria entre a Secretaria Municipal de Saúde, a Secretaria de Segurança Pública (Corpo de Bombeiros) e a Secretaria Estadual de Saúde. Proporciona atenção pré-hospitalar, principalmente a vítimas de trauma causado, em sua grande maioria, por acidentes de transporte. No período de 1997 a 2000, esse serviço atendeu 26.954 pessoas, e os acidentes de transporte terrestre (de trânsito, em especial) foram responsáveis por mais de $50,0 \%$ do total desses atendimentos 6 .

Considerando que o primeiro passo para o estudo de um agravo é a descrição exata e minuciosa de como ele acontece na população, ou seja, qual a sua ocorrência por tempo, lugar e pessoas 7, e que o conhecimento dos diferentes tipos de acidentes e suas vítimas se constitui em um orientador fundamental para a definição de políticas de prevenção e controle desses agravos e das mortes por eles causados 8 , o presente trabalho tem como principal objetivo estudar as características epidemiológicas dos acidentes de trânsito e das vítimas atendidas pelo SIATE de Londrina no período de 1997 a 2000.

\section{Material e métodos}

Foram estudadas todas as vítimas de acidentes de trânsito atendidas pelo SIATE, no período de 1997 a 2000, as quais foram atendidas na região metropolitana de Londrina, que se constitui a área de abrangência desse serviço. A maioria dos atendimentos, contudo, ocorre na própria zona urbana do município.

A pesquisa baseou-se no banco de dados eletrônico do SIATE, construído por meio do programa Epi Info. Esse banco, construído em 1996, à época da implantação do Serviço, era, até 2001 , continuamente alimentado com informações sobre as circunstâncias do acidente/violência, codificadas pela Classificação Internacional de Doenças, décima revisão (CID10) 4 ,9. Embora não haja estudos que analisem a cobertura do SIATE em relação às vítimas de acidentes de trânsito na cidade, sabe-se que o número de vítimas atendidas é cerca de 50,0\% superior ao número registrado em boletins de ocorrência policial.

Para o presente estudo, foram selecionadas as vítimas de acidentes de transporte terrestre (códigos V01 a V89 da CID-10) 9, que se constituem, predominantemente, em acidentes de trânsito (ocorridos na via pública). Embora alguns poucos casos que não ocorreram na via pública possam ter sido incorporados na análise, decidiu-se pela terminologia acidente de "trânsito", por esta ser a mais conhecida e por constituir mais de 99,0\% dos casos de acidentes de transporte terrestre. Esses dados foram direcionados a um novo arquivo, no qual foram realizadas diversas tabulações para verificação de inconsistências, como, por exemplo, ciclista com informação de uso de cinto de segurança. Nesses casos, retornava-se ao prontuário da vítima, realizando as correções necessárias. A taxa de erros observada foi inferior a $1,0 \%$, o que indica que a qualidade da informação do próprio serviço é boa.

As variáveis estudadas em relação às vítimas foram: sexo, idade (agrupada em faixas etárias a cada dez anos) e tipo de vítima (caracterizado pelo papel desempenhado pela vítima no momento do acidente, de acordo com o capítulo XX, códigos de V01 a V89 da CID-10) 9. As variáveis relacionadas ao acidente foram: horário de ocorrência (agrupado em manhã: $6 \mathrm{~h}$ às $11 \mathrm{~h} 59 \mathrm{~min}$; tarde: $12 \mathrm{~h}$ às $17 \mathrm{~h} 59 \mathrm{~min}$; noite: $18 \mathrm{~h}$ às 23h59min; madrugada: $0 \mathrm{~h}$ às $5 \mathrm{~h} 59 \mathrm{~min}$ ) e dias 
da semana (detalhadamente, de segunda a domingo), dicotomizados em dias úteis (de segunda a sexta-feira) e finais de semana (sábado e domingo).

Todos os dados e indicadores foram calculados para os anos de 1997 a 2000, sendo apresentados em tabelas por meio de números absolutos e percentuais.

Este trabalho foi aprovado pelo Comitê de Ética em Pesquisa da Universidade Estadual de Londrina.

\section{Resultados e discussão}

No período de 1997 a 2000, o SIATE de Londrina atendeu 14.474 vítimas de acidentes de trânsito. A grande maioria era do sexo masculino, com valores que variaram de $72,4 \%$ em 1998 a $75,2 \%$ em 2000. Esses resultados são semelhantes aos de diversos estudos nacionais que apontam a predominância do sexo masculino (acima de $60,0 \%$ do total) entre as vítimas de acidentes de trânsito 2,5,8,10,11,12,13,14,15.

O predomínio de homens entre as vítimas que não morreram $5,10,11$ ou que foram a óbito 8 por lesões decorrentes de acidentes de trânsito, inclusive entre crianças, ilustra muito bem o efeito dos padrões sócio-culturais, cristalizados na noção de gênero, sobre este perfil, pois, em princípio, parece não haver fator biológico que explique a maior predisposição masculina em morrer por esse tipo de lesão 16 .

A distribuição das vítimas por grupo etário (Tabela 1) variou muito pouco entre os quatro anos de estudo. A faixa etária predominante foi a de 20 a 29 anos, com valores sempre superiores a $30,0 \%$. Em segundo e terceiro lugares estão as faixas de 10 a 19 e de 30 a 39 anos, respectivamente. No conjunto das vítimas, as crianças de 0 a 9 anos aumentaram gradativamente sua participação proporcional, passando de 4,8\% em 1997 para 6,5\% em 2000. A grande maioria das vítimas, em todos os anos, tinha de 10 a 39 anos (mais de 70,0\% dos casos).

Diversas pesquisas nacionais têm resultados condizentes com os do presente estudo e relatam que cerca de 70,0\% das vítimas de acidente de trânsito têm idade entre 10 e 39 anos. Pertencem, portanto, ao grupo de adolescentes e adultos jovens $5,11,12,14,17,18$.

Segundo Mattox et al. 19, em países desenvolvidos, a maioria dos ferimentos fatais e não fatais por acidentes de trânsito também ocorre em jovens. Na Comunidade Européia, pessoas abaixo dos 45 anos respondem por $61,0 \%$ do total de mortes por trauma, $62,0 \%$ das hospitalizações e $80,0 \%$ dos atendimentos nos setores de emergência dos hospitais.

Teorias sobre o comportamento têm algumas hipóteses explicativas para o fato de os adolescentes e adultos jovens serem mais acometidos por acidentes e violências. Inexperiência, busca de emoções, prazer em experimentar sensações de risco, impulsividade e abuso de álcool ou drogas são termos associados aos comportamentos de adolescentes e adultos jovens que podem contribuir para a maior incidência de acidentes de trânsito nessas faixas etárias 20. Estudo realizado na Austrália revelou

Tabela 1

Número e proporção de vítimas de acidentes de trânsito atendidas pelo Serviço Integrado de Atendimento ao Trauma e às Emergências (SIATE), por faixa etária e ano. Londrina, Paraná, Brasil, 1997 a 2000.

\begin{tabular}{|c|c|c|c|c|c|c|c|c|}
\hline \multirow[t]{3}{*}{ Faixa etária (anos) } & \multicolumn{8}{|c|}{ Ano } \\
\hline & \multicolumn{2}{|c|}{1997} & \multicolumn{2}{|c|}{1998} & \multicolumn{2}{|c|}{1999} & \multicolumn{2}{|c|}{2000} \\
\hline & $\mathrm{n}$ & $\%$ & $\mathrm{n}$ & $\%$ & $\mathrm{n}$ & $\%$ & $\mathrm{n}$ & $\%$ \\
\hline $0-9$ & 170 & 4,8 & 173 & 5,0 & 195 & 5,5 & 251 & 6,5 \\
\hline $10-19$ & 797 & 22,3 & 748 & 21,6 & 712 & 19,9 & 770 & 19,9 \\
\hline $20-29$ & 1.246 & 34,9 & 1.263 & 36,5 & 1.222 & 34,2 & 1.279 & 33,0 \\
\hline $30-39$ & 662 & 18,6 & 602 & 17,4 & 732 & 20,5 & 770 & 19,9 \\
\hline $40-49$ & 328 & 9,2 & 344 & 9,9 & 342 & 9,6 & 412 & 10,6 \\
\hline $50-59$ & 176 & 4,9 & 175 & 5,1 & 192 & 5,4 & 193 & 5,0 \\
\hline $60-69$ & 113 & 3,2 & 84 & 2,4 & 100 & 2,8 & 124 & 3,2 \\
\hline $70-79$ & 49 & 1,4 & 57 & 1,6 & 52 & 1,5 & 54 & 1,4 \\
\hline 80 e mais & 16 & 0,4 & 12 & 0,3 & 20 & 0,6 & 18 & 0,5 \\
\hline Total* & 3.557 & 100,0 & 3.458 & 100,0 & 3.567 & 100,0 & 3.871 & 100,0 \\
\hline
\end{tabular}

* Exclui 21 vítimas com idades ignoradas. 
que $43,0 \%$ dos motoristas envolvidos nesses acidentes, presos por estarem embriagados, tinham idade entre 18 e 25 anos 21 .

Conforme os dados da Tabela 2, os motociclistas foram o principal tipo de vítima em todos os anos, com valores sempre superiores a $40,0 \%$, variando de 41,6\% em 2000, a 45,5\% em 1998.

Outros estudos realizados em Londrina também apontam os motociclistas como principal tipo de vítima de acidente de trânsito, com valores superiores a $40,0 \%$, seja entre sobreviventes, seja entre as vítimas que foram a óbito 5,11 . Em cidades como Pelotas (Rio Grande do Sul) 10, Maringá (Paraná) 18 e Campinas (São Paulo) 22, além de outras 23,24 , os motociclistas também estão entre as principais vítimas de acidente de trânsito, juntamente com os pedestres, o que tem sido atribuído ao aumento do uso de motocicletas como instrumento de trabalho, na maioria das vezes informal (entrega de mercadorias, serviços ou transporte de pessoas) 5,10 . Assim, o estudo das particularidades desses acidentes pode contribuir para subsidiar a adoção de estratégias específicas de prevenção dessas ocorrências.

Acidentes com motocicletas resultam, freqüentemente, em ferimentos graves para condutores e passageiros; portanto, os motociclistas devem ser considerados mais vulneráveis em relação aos usuários de outros tipos de veículos automotores 5,25,26 e necessitam de medidas específicas e urgentes no sentido de conter o crescente número dessas vítimas no Brasil 10,22. Além disso, os motociclistas, comumente, colocam em risco a integridade de outros usuários da via pública, especialmente pedestres 10 .

Os ocupantes de auto/caminhonete, neste estudo, vêm a seguir com percentuais superiores a $20,0 \%$, apresentando, porém, redução da proporção no período analisado (de 29,5\% em 1997 para $24,6 \%$ em 2000).

Resultados semelhantes aos deste trabalho foram encontrados por Andrade \& Mello-Jorge 5 e Marson \& Thomson 27, para a cidade de Londrina, onde cerca de $20,0 \%$ das vítimas de acidente de trânsito eram ocupantes de auto/caminhonete. Já nos países desenvolvidos, em geral, o principal tipo de vítima são os ocupantes de automóveis. Na Suíça, pesquisa realizada sobre motoristas jovens envolvidos em acidentes de trânsito classificou como ocupantes de automóvel a maioria das vítimas 28 .

Comparando o elevado percentual de veículos do tipo auto/caminhonete no Município de Londrina (65,0\% do total), segundo dados do Departamento de Trânsito do Paraná, com o percentual de vítimas ocupantes desse tipo de veículo encontrado nesse estudo (pouco mais de 20,0\%), esse valor pode ser considerado pequeno. Podemos atribuir o percentual relativamente baixo desse tipo de vítima, provavelmente, à proteção que é conferida aos ocupantes pelo próprio veículo ou pelo uso do cinto de segurança.

Os ciclistas, que ocuparam o terceiro lugar em todos os anos, apresentaram o maior aumento na proporção de vítimas, passando de 13,0\% em 1997 para 18,3\% em 2000.

Segundo Tapia-Granados 16, o risco de morte em um acidente de trânsito para um ciclista, no Reino Unido, é cinco vezes maior do que para um ocupante de automóvel. De acordo com esse autor, analisando os dados sobre acidentes de trânsito em diversos países, a maioria das vítimas que vão a óbito é composta por pedestres e ciclistas.

Em um estudo realizado em Belo Horizonte (Minas Gerais) sobre as características das pes-

Número e proporção de vítimas de acidentes de trânsito atendidas pelo Serviço Integrado de Atendimento ao Trauma e às Emergências (SIATE), por tipo de vítima e ano. Londrina, Paraná, Brasil, 1997 a 2000.

\begin{tabular}{|c|c|c|c|c|c|c|c|c|}
\hline \multirow[t]{3}{*}{ Tipo de vítima } & \multicolumn{8}{|c|}{ Ano } \\
\hline & \multicolumn{2}{|c|}{1997} & \multicolumn{2}{|c|}{1998} & \multicolumn{2}{|c|}{1999} & \multicolumn{2}{|c|}{2000} \\
\hline & $\mathrm{n}$ & $\%$ & $\mathrm{n}$ & $\%$ & $\mathrm{n}$ & $\%$ & $\mathrm{n}$ & $\%$ \\
\hline Motociclista & 1.546 & 43,4 & 1.577 & 45,5 & 1.572 & 44,0 & 1.603 & 41,6 \\
\hline Ocupante de carro* & 1.051 & 29,5 & 895 & 25,8 & 889 & 24,9 & 961 & 24,6 \\
\hline Ciclista & 465 & 13,0 & 477 & 13,8 & 603 & 16,9 & 709 & 18,3 \\
\hline Pedestre & 407 & 11,3 & 407 & 11,7 & 410 & 11,5 & 488 & 12,6 \\
\hline Caminhão/ônibus/outros & 99 & 2,8 & 108 & 3,1 & 97 & 2,7 & 110 & 3,0 \\
\hline Total & 3.568 & 100,0 & 3.464 & 100,0 & 3.571 & 100,0 & 3.871 & 100,0 \\
\hline
\end{tabular}

* Inclui ocupante de caminhonete. 
soas envolvidas em acidentes com veículos de duas rodas, $40,0 \%$ das vítimas eram ciclistas. Como fatores causais deste tipo de acidente, os autores apontam o fato de a maioria dos ciclistas utilizarem a bicicleta como uma forma de lazer, o que reduz a consciência de risco e as medidas de prevenção que deveriam ser adotadas, além da falta de ciclovias 24 .

Deficiências no meio ambiente (ausência de ciclovias), maior exposição do ciclista a ferimentos, pela proximidade com o solo e pela desigualdade cinética (força, velocidade e massa) existente entre a bicicleta e os veículos automotores, e o aumento do uso da bicicleta como meio de transporte, provavelmente, devem estar contribuindo para que o número de vítimas ciclistas venha aumentando durante os últimos anos na cidade em estudo. Essa realidade, associada com a não-exigência de treinamento ou habilitação para a condução desse tipo de veículo e com o comportamento inadequado de alguns motoristas de carros e ciclistas no trânsito, pode estar contribuindo para a ocorrência desses acidentes.

Em quarto lugar, em todos os anos do estudo, aparecem os pedestres, com um percentual praticamente constante no período, acima de $11,0 \%$, passando para $12,6 \%$ no ano de 2000 , achados semelhantes aos encontrados por Andrade \& Mello-Jorge 5 e Soares 18, em Londrina e Maringá, respectivamente. Apesar de constarem na quarta posição entre os tipos de vítimas atendidas pelo SIATE de Londrina, esse resultado não pode ser menosprezado, pois os pedestres são as vítimas com maior probabilidade de serem internadas ou morrerem após terem sofrido um acidente 10,29. No Brasil, nos acidente de trânsito, a maioria das vítimas que vão a óbito são pedestres, e estes respondem por cerca de $50,0 \%$ do total das hospitalizações por lesões causadas por esses acidentes 13,15,30.

Historicamente, as ações voltadas para a organização das vias públicas e o seu tráfego têm privilegiado o trânsito dos veículos motorizados, o que deixa os pedestres em situação de desvantagem em relação aos motoristas e passageiros, gerando um elevado número de atropelamentos 31 . A velocidade dos veículos automotores é considerada também um fator importante para a ocorrência de atropelamentos. Anderson et al. 32 relatam que a redução da velocidade dos veículos em $10 \mathrm{~km} / \mathrm{h}$ pode diminuir em 48,0\% o número de vítimas desse tipo de acidente, além disso, 10,0\% dos acidentes fatais podem ser evitados, já que o veículo poderia parar antes de atingir o pedestre. Esforços a fim de mudar o comportamento dos pedestres por meio da educação também são im- portantes, mas surtem menos efeito do que ações que tenham como objetivo modificar o meio ambiente físico e social do sistema de transportes 33 .

Segundo o Centers for Disease Control and Prevention, nos Estados Unidos, as taxas de mortes de pedestres declinaram 41,0\% de 1975 a 1997, mas ainda representam $13,0 \%$ do total de óbitos relacionados a acidentes de trânsito nesse país 34 . Os fatores apontados como responsáveis por essa redução incluem maior número e melhor qualidade das calçadas, parques infantis longe das ruas, fluxo de tráfego em mão única e restrições para estacionamento de veículos nas ruas, além do encorajamento de comportamentos seguros aos pedestres.

O menor percentual de vítimas, em todos os anos, foi o do grupo dos ocupantes de veículos pesados e outros (caminhão, ônibus), que respondeu por $2,7 \%$ a $3,0 \%$ do total de vítimas, em 1998 e 2000, respectivamente.

Os ocupantes de veículos pesados, provavelmente, têm menor chance de sofrer ferimentos causados por acidentes de trânsito em virtude da proteção a eles conferida pelo tamanho do veículo, principalmente nas áreas urbanas, onde eles têm sua velocidade diminuída por causa do volume do tráfego e das condições das vias públicas.

Ao analisarmos as características dos acidentes com relação ao dia da semana de sua ocorrência, observou-se uma elevação do número de vítimas a partir da sexta-feira, com maior concentração no sábado, cerca de $20,0 \%$ do total, em todos os anos de estudo.

Esses resultados mostraram-se semelhantes aos encontrados na literatura, pois há unanimidade entre alguns autores quanto à maior ocorrência de acidentes de trânsito e de vítimas nos finais de semana 10,29,35,36. No entanto, Doherty et al. 36 consideraram como fim de semana a sexta-feira e o sábado, omitindo o domingo de sua análise.

Alguns autores relacionam a maior ocorrência de acidentes nos finais de semana com a possível ingestão de bebidas alcoólicas pelos motoristas, mais freqüente nesses períodos 17 , 29,37,38. Em Londrina, a maioria das festas, principalmente as promovidas por estudantes universitários para arrecadação de fundos para sua formatura, ocorre nos finais de semana e nessas ocasiões o consumo de álcool entre os participantes é elevado.

Com relação ao mês de ocorrência do acidente, dezembro foi o que mais produziu vítimas em todos os anos de estudo (acima de $10,0 \%$ ), exceto em 1997, quando ficou na segunda posição, perdendo para agosto por uma 
vítima. Esse resultado, possivelmente, deve-se ao fato de Londrina se constituir pólo regional de compras e serviços, atraindo grande contingente populacional nessa época do ano.

A distribuição das vítimas por horário de ocorrência do acidente nos diferentes anos de estudo foi muito semelhante, tendo sua maior concentração nos horários da noite (18h às 23h59min) e tarde (12h às 17 h59min).

Pesquisa realizada em Londrina, em 1996, encontrou um maior número médio de vítimas em acidentes ocorridos nos períodos da tarde e noite, e, em dias úteis, a maioria das vítimas acidentou-se no horário de retorno de suas atividades (18h às $19 \mathrm{~h}$ ). Isso sugere que essa ocorrência possa se dever ao cansaço, que é maior no final do dia, e também ao elevado fluxo de veículos nesse horário 29.

Normalmente o horário da noite é o de maior incidência de vítimas, uma vez que nesse período, geralmente, os acidentes apresentam maior gravidade, em virtude de diversos fatores ligados ao meio ambiente (menor visibilidade) e aos usuários da via pública (excesso de velocidade, desrespeito aos semáforos, uso de álcool e drogas, entre outros).

O elevado índice de vítimas no período noturno e nos fins de semana deveria servir como indicador para a criação e implementação de programas intersetoriais de prevenção de acidentes de trânsito direcionados aos jovens, que, apenas pela sua idade e inexperiência, já constituem um grupo de risco para esse tipo de acidente.

Campanhas educativas bem-humoradas de esclarecimento quanto aos riscos do uso de álcool e direção, aos fatores ambientais que dificultam a direção de veículos automotores durante a noite e aos demais comportamentos de risco para esses acidentes poderiam ser realizadas, aproveitando a grande concentração de jovens em casas noturnas, restaurantes e bares nos finais de semana.

Modificações no meio ambiente, como melhoria da sinalização, da iluminação, do sistema de tráfego e das vias públicas, também são fundamentais para a redução de acidentes de trânsito, e só podem ser implementadas através de ações intersetoriais 22,39. Também, a fiscalização do trânsito deveria ser intensificada nesses períodos, facilitando a punição dos motoristas infratores, diminuindo, assim, o número de acidentes e vítimas desses acidentes em Londrina.

\section{Conclusões e recomendações}

O levantamento das características epidemiológicas da população atingida por um determinado agravo, a caracterização do seu comportamento ao longo do tempo e o conhecimento dos grupos mais expostos possibilitam a criação e implantação de estratégias de prevenção que podem diminuir os riscos e suas conseqüências. Apesar de algumas limitações, acredita-se que este estudo conseguiu traçar o perfil das vítimas estudadas, fornecendo informações importantes sobre os grupos de risco para acidentes de trânsito, que poderão oferecer subsídios para ações preventivas e de controle, em relação tanto à morbidade quanto à mortalidade dessas vítimas, no Município de Londrina.

O predomínio do sexo masculino entre as vítimas desses acidentes ficou bastante evidente neste trabalho. Programas de educação para o trânsito, com técnicas pedagógicas adequadas, deveriam ser desenvolvidos e implementados, visando atingir esses grupos de risco (adolescentes e jovens, principalmente os do sexo masculino).

Como os motociclistas foram o principal tipo de vítima durante os quatro anos de observação, atenção especial deveria ser dada a esse grupo no planejamento de ações preventivas e de controle de acidentes de trânsito em Londrina. Considerando o número elevado de motociclistas circulando na cidade em situações de trabalho, serviços de tele-entrega ou transporte de passageiros, algumas ações poderiam ser propostas, tais como: ampliar os estudos a respeito desses usuários da via pública (condições de trabalho, do veículo, dos comportamentos no trânsito e dos riscos de acidentes); articular pessoas de diferentes especialidades interessadas na temática para a discussão de ações interdisciplinares e intersetoriais, visando à melhoria da segurança no tráfego e à redução desses acidentes; buscar caminhos de integração com as empresas que se utilizam desses serviços e com representantes das categorias profissionais envolvidas nesse tipo de transporte, a fim de ampliar a discussão e definir estratégias mais específicas de intervenção.

De acordo com os resultados deste estudo, em relação aos dias e horários de maior ocorrência de acidentes, a fiscalização por parte da polícia de trânsito deveria ser intensificada nos finais de semana, nos horários da noite e tarde e durante o mês de dezembro.

Existe uma tendência em se focalizar o ônus da segurança no trânsito apenas nos usuários das vias públicas, de forma individual. No entanto, é inaceitável que os governantes absol- 
vam a si próprios da responsabilidade sobre esses eventos. Somente ações intersetoriais que contemplem a prevenção dos acidentes de trânsito em todos os seus aspectos, executadas de forma coordenada, podem reduzir tais acidentes, suas vítimas e as mortes por eles causadas.

Finalmente, há que se destacar a importância de dados secundários, como os utilizados no presente estudo, na análise da morbidade causada por acidentes de trânsito. No Brasil, a única base de dados nacional sobre morbidade atualmente disponível ao público é a do Sistema de Informações Hospitalares do Sistema Único de Saúde (SIH-SUS). Essa fonte de informações é de caráter não universal, pois se restringe às internações do SUS, excluindo parcela importante da população que não necessita de internação ou que é atendida pelo sistema

\section{Resumo}

Os acidentes de trânsito e os traumas deles resultantes constituem um importante problema social e de saúde pública. O objetivo deste trabalho foi o de analisar as características dos acidentes e das vítimas atendidas pelo único serviço de atenção pré-hospitalar de Londrina, Paraná, Brasil, o Serviço Integrado de Atendimento ao Trauma e às Emergências (SIATE), de 1997 a 2000. Foram estudadas 14.474 vítimas registradas no banco de dados do SIATE. Em todos os anos de estudo, mais de 70,0\% das vítimas eram do sexo masculino e tinham de 10 a 39 anos; os motociclistas foram o principal tipo de vítima em todos os anos, com valores superiores a 40,0\%. A maioria acidentou-se no mês de dezembro, nos finais de semana, principalmente no sábado, e durante a noite. Esses resultados corroboram os observados em outros estudos, evidenciando a necessidade de implementação de medidas preventivas direcionadas à população jovem e masculina, especialmente a composta por motociclistas.

Acidentes de Trânsito; Serviços de Saúde; Serviços Médicos de Emergência

\section{Colaboradores}

Y. G. L. Bastos coletou e revisou os dados da pesquisa, realizou as tabulações e análises, redigiu a versão preliminar do artigo e participou da edição e revisão da versão final. S. M. Andrade orientou o trabalho de pesquisa, participou nas análises e na edição e revisão final do artigo. D. A. Soares participou na orientação do trabalho, nas análises e na edição e revisão final do artigo. privado ou coberta por planos de saúde. A construção e manutenção de um banco de dados sobre vítimas de acidentes de trânsito atendidas na fase pré-hospitalar, como o do SIATE de Londrina, além de possibilitar o monitoramento da ocorrência dessas causas na população, facilita a estratégia de ligação de bancos de dados com o intuito de verificar fatores associados ao maior risco de óbito, seqüelas ou outras conseqüências desses tipos de acidentes. Portanto, esforços deveriam ser empreendidos, pelo poder público, a fim de manter atualizadas essas informações ao público e aos pesquisadores interessados, tornando-as disponíveis, a exemplo do que já ocorre com as informações sobre mortalidade e internações públicas no Brasil.

\section{Referências}

1. Delattorre MCC. O trânsito e seus novos centauros [Dissertação de Mestrado]. Londrina: Universidade Estadual de Londrina; 1997.

2. Marín L, Queiroz MS. A atualidade dos acidentes de trânsito na era da velocidade: uma visão geral. Cad Saúde Pública 2000; 16:7-21.

3. Wolf W. Car mania: a critical history of transport Chicago: Pluto Press; 1996.

4. Prefeitura Municipal de Londrina, Secretaria Municipal de Saúde. Acidentes "roubam" 3 mil anos de vida. Boletim Informativo da Saúde 2001; 26:4.

5. Andrade SM, Mello-Jorge MHP. Características das vítimas de acidentes de transporte terrestre em município da Região Sul do Brasil. Rev Saúde Pública 2000; 34:149-56.

6. Prefeitura Municipal de Londrina, Secretaria Municipal de Saúde. Acidentes de transporte são a primeira causa de atendimento do SIATE. Boletim Informativo de Saúde 2001; 28:3.

7. Barata RCB. O desafio das doenças emergentes e a revalorização da epidemiologia descritiva. Rev Saúde Pública 1997; 33:531-7.

8. Mello-Jorge MHP, Gawryszewski VP, Latorre MRDO. Análise dos dados de mortalidade. Rev Saúde Pública 1997; 31(4 Suppl):5-25.

9. Organização Mundial da Saúde. Classificação estatística internacional de doenças e problemas relacionados à saúde, 10a revisão. v. 1. São Paulo: Centro Colaborador da OMS para a Classificação de Doenças em Português; 1995.

10. Barros AJD, Amaral RL, Oliveira MSB, Lima SC, Gonçalves EV. Acidentes com vítimas: sub-registro, caracterização e letalidade. Cad Saúde Pública $2003 ; 19: 979-86$.

11. Bastos YGL, Andrade SM, Cordoni Jr. L. Acidentes de trânsito e o novo Código de Trânsito Brasileiro 
em cidade da Região Sul do Brasil. Inf Epidemiol SUS 1999; 8:37-45.

12. Brito EM, Costa GR, Alves RS, Meneses EA, Duarte SC. Traumatismo crânio-encefálico em vítimas de acidentes de trânsito atendidas no Hospital de Base do Distrito Federal em 1994 e 1995. Rev Saúde Dist Fed 1996; 7:41-9.

13. Klein CH. Mortes no trânsito do Rio de Janeiro, Brasil. Cad Saúde Pública 1994; 10 Suppl 1:16876.

14. Liberatti CLB, Andrade SM, Soares DA. The new Brazilian traffic code and some characteristics of victims in southern Brazil. Inj Prev 2001; 7:190-3.

15. Sallum AM, Koizumi MS. Natureza e gravidade das lesões em vítimas de acidente de trânsito de veículo a motor. Rev Esc Enfermagem USP 1999; 33:157-64.

16. Tapia-Granados JA. La reducción del tráfico de automóviles: una política urgente de promoción de la salud. Rev Panam Salud Pública 1998; 3:13751.

17. Minayo MCS. Violência social sob a perspectiva da saúde pública. Cad Saúde Pública 1994; 10 Suppl 1:7-18.

18. Soares DFPP. Vítimas de acidentes de trânsito ocorridos no perímetro urbano de Maringá - PR [Dissertação de Mestrado]. Londrina: Universidade Estadual de Londrina; 1997.

19. Mattox KL, Feliciano DV, Moore EE. Trauma. New York: McGraw-Hill; 2000.

20. Robertson LS. Injury epidemiology. New York: Oxford University Press; 1998

21. Rosman DL, Ferrante AM, Marom Y. A linkage study of Western Australian drink driving arrests and road crash records. Accid Anal Prev 2000; 33: 211-20.

22. Queiroz MS, Oliveira PCP. Acidentes de trânsito: uma visão qualitativa no Município de Campinas, São Paulo, Brasil. Cad Saúde Pública 2002; 18:117987.

23. Calil AM. Natureza da lesão e gravidade do trauma segundo qualidade das vítimas de acidente de trânsito de veículo a motor [Dissertação de Mestrado]. São Paulo: Escola de Enfermagem, Universidade de São Paulo; 1997.

24. Gonçalves RM, Petroianu A, Júnior JRF. Características das pessoas envolvidas em acidentes com veículos de duas rodas. Rev Saúde Pública 1997; 31:436-7.

25. Koizumi MS. Padrão das lesões nas vítimas de acidentes de motocicleta. Rev Saúde Pública 1992; 26:306-16
26. Thompson DC, Thompsom RS, Rivara FP. Risk compensation theory should be subject to systematic reviews of the scientific evidence. Inj Prev 2001; 7:86-8

27. Marson AC, Thomson JC. The influence of pre hospital trauma care on motor vehicle crash mortality. J Trauma 2001; 50:917-21.

28. Murray A. The home and school background of young drivers involved in traffic accidents. Accid Anal Prev 1998; 29:169-82.

29. Andrade SM, Mello-Jorge MHP. Acidentes de transporte terrestre em município da Região Sul do Brasil. Rev Saúde Pública 2001; 35:318-20.

30. Mello-Jorge MHP, Latorre MRDO. Acidentes de trânsito no Brasil: dados e tendências. Cad Saúde Pública 1994; 10 Suppl 1:19-44.

31. Faria EO, Braga MGC. Propostas para minimizar os riscos de acidentes de trânsito envolvendo crianças e adolescentes. Ciênc Saúde Coletiva 1999; 4:99-107.

32. Anderson RWG, McLean AJ, Farmer MJB, Lee BH, Brooks CG. Vehicle travel speeds and the influence of fatal pedestrian crashes. Accid Anal Prev 1997; 29:667-74.

33. Harruff RC, Avery A, Alter-Pandia AS. Analysis of circumstances and injuries in pedestrian traffic fatalities. Accid Anal Prev 1998; 30:11-20.

34. Centers for Disease Control and Prevention. Motor-vehicle safety: a $20^{\text {th }}$ century public health achievement. JAMA 1999; 281:2080-2.

35. Ladeira RM. Morbi-mortalidade por acidentes de trânsito em cinco hospitais de Belo Horizonte e Contagem [Dissertação de Mestrado]. Belo Horizonte: Faculdade de Medicina, Universidade Federal de Minas Gerais; 1995.

36. Doherty ST, Andrey JC, MacGregor C. The situational risks of young drivers: the influence of passengers, time of day and day of week on accident rates. Accid Anal Prev 1998; 30:45-52.

37. Koelega HS. Alcohol and vigilance performance: a review. Psychopharmacology (Berl) 1995; 118: 233-49.

38. Voas RB, Wells J, Lestina D, Williams A, Greene M. Drinking and driving in the United States: the 1996 National Road Side Survey. Accid Anal Prev 1998; 30:267-75.

39. Johnston I. Actions to reduce road casualties. World Health Forum 1992; 13:154-62.

Recebido em 03/Mar/2004

Versão final reapresentada em 18/Ago/2004

Aprovado em 04/Nov/2004 